\title{
The effect of bentonite feeding for young cattle on the exchange of nitrogen, mineral elements and the digestibility of diet nutrients
}

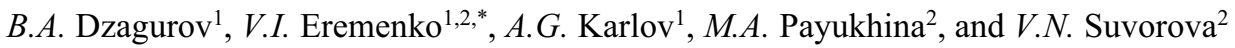 \\ ${ }^{1}$ Gorsky State Agrarian University, North Ossetia-Alania, Kirova str., 37, 362040 Vladikavkaz, \\ Russia \\ ${ }^{2}$ Kursk State Agricultural Academy named after I.I. Ivanov, K. Marxa str., 70, 305021 Kursk, Russia
}

\begin{abstract}
The completeness of animal nutrition rations in terms of the content of minerals is considered one of the conditions for balanced feeding, since their lack in the diet often leads to metabolic process disorder among animals, which reduces growth and development, productivity, disturbs reproductive ability, and develops endemic diseases. Currently, for the partial compensation of trace mineral deficiency in the diets of use mineral substances of natural origin. One of such sources is bentonite clay of the Zamankul deposit. Taking into account the significant increase of the economically useful traits among young cattle identified in our studies when feeding with bentonite, substantiated by physiological studies, we performed research to study the exchange of nitrogen, mineral elements and the digestibility of nutrients in the body of $9-18$-month-old cattle of the Simmental breed for fattening at the farm "Kaloev", stanitsa Zmeyskaya, North Ossetia-Alania. Studies have established the digestibility of nutrient increase in the feed ration from 1.8 to $3.5 \%$, a significantly greater retention of nitrogenous substances in the body of animals fed with bentonite - by $8.2 \%$, a significant improvement of mineral element use in the feed.
\end{abstract}

\section{Introduction}

It is known that the forages produced on the foothills of the North Caucasus, lack a number of mineral elements [1,2]. In order to compensate for this deficiency, experts use carbonic and sulfate salts of macro- and microelements when balancing feed rations, which are considered expensive and ecologically unsafe $[3,4,5,6]$. Based on the results of our scientific and economic experiment [7] on the fattening livestock, when feeding with bentonite in the amount of $1 \%$ of the dry weight of the feed, at which a significant increase in live weight was established among young cattle by $8.3 \%$, the feed conversion - by $4.6 \%$, it seemed relevant to substantiate the obtained productive indicator theoretically by

\footnotetext{
* Corresponding author: vic.eriomenko@yandex.ru
} 
studying the exchange of nitrogen, mineral elements and the digestibility of nutrients in the diet of experimental animals [8,9].

In this regard, the aim of the research was to study the effect of feeding young animals with bentonite clay on fattening, on the exchange of nitrogen, calcium, phosphorus, iron, manganese, copper, zinc, cobalt and the digestibility of nutrients in the feeding diet of animals.

\section{Material and research methods}

To conduct research during the period of scientific and economic experience, a physiological (balance) experiment was carried out according to the method by N.I. Ovsyannikov (1967) and N.I. Platikanov (1967) among 17-month-old animals. Samples were selected according to the principle of analogous pairs, three animals each, with a characteristic live weight for the live group. The samples were selected for the studies from the control group (who received the main diet) and the experimental group (fed additionally to the main diet with $69.3 \mathrm{~g}$ of bentonite with compound feed $(1 \%$ of the dry weight of the feed). During the physiological experiment ( 7 days - preliminary period and 5 days accounting period), the feed intake was taken into account by weighing the assigned feed and their residues. Average samples of feed, feces and urine were taken according to the method described by VIZH (N.P. Drozdenko et al., (1981), P.I. Viktorov et al. (1988). In this case, laboratory analyzes were carried out in the agroecology laboratory of the Gorsky State Agrarian University: dry matter in food and feces samples were studied by drying in a thermostat at the temperature of $105{ }^{\circ} \mathrm{C}$; feed and feces nitrogen - according to Kjeldal; "raw" fat - in the Soxhlet apparatus; according to the method by S.V. Rushkovsky; "raw" fiber - according to Henneberg and Shtoman; "raw" ash - by ashing in a muffle furnace at the temperature of $500{ }^{\circ} \mathrm{C}$; NFES - by calculation; calcium - by complexometric method; phosphorus - calorimetrically; microelements - on a "Sudi" like polariograph. The urine was evaporated in a water bath, the dry residue was ashed in a muffle furnace and subjected to further studies according to the methods described above. On the basis of laboratory analyzes of feed, feces and urine samples, they calculated the indicators of nitrogen, and mineral element exchange and the coefficients of the diet nutrients.

\section{Research results and their discussion}

The digestibility of nutrients in the diet of growing animals largely depends not only on the level of feeding, but also on the feed preparation technology, the ratio of different types of feed in the diet, the presence of nutrients and minerals in them, as well as the inclusion of various feed additives in the diet.

After the physiological (balance) experiment on the fattening livestock and calculations of feed nutrient digestibility, it was found that feeding the animals of the experimental group with bentonite contributed to nutrient digestibility increase in the feed ration (Table $1)$.

Table 1. Nutrient digestibility rates, $\%$

\begin{tabular}{|l|c|c|}
\hline \multirow{2}{*}{ Indicator } & \multicolumn{2}{|c|}{ Group } \\
\cline { 2 - 3 } & control & experimental \\
\hline Dry matter & $65,3 \pm 0,42$ & $67,5 \pm 0,48$ \\
\hline Organic matter & $65,7 \pm 0,49$ & $69,2 \pm 0,46$ \\
\hline "Crude" protein & $65,7 \pm 0,29$ & $68,1 \pm 0,34$ \\
\hline "Raw" fat & $64,5 \pm 0,42$ & $67,3 \pm 0,49$ \\
\hline
\end{tabular}




\begin{tabular}{|l|c|c|}
\hline "Raw" fiber & $57,6 \pm 0,38$ & $59,4 \pm 0,42$ \\
\hline NFES & $79,6 \pm 0,58$ & $82,3 \pm 0,60$ \\
\hline
\end{tabular}

From the results shown in Table 1 it follows that feeding the animals of the experimental group with bentonite, in comparison with the control one, provided a high level of digestion processes, due to the content of mineral elements in bentonite, including vital ones that have a catalytic effect on biochemical processes in digestive metabolism, and physicochemical properties of bentonite on the digestive processes (sorption and ionexchange capacity, catalytic and surface activity, etc.) previously established in other studies $[2,4]$. Thus, the animals of the experimental group, relative to the control analogs, digested better dry matter of the diet by $2.2 \%$, organic matter by $3.5 \%$, "crude" protein - by $2.4 \%$, "crude" fat - by $2,8 \%$, "crude" fiber - by $1.8 \%$ and NFES - by $2.7 \%$ (P $\leq 0.01)$.

Consequently, the calculations established that feeding young cattle with bentonite from the Zamankul deposit had a positive effect on the digestibility and use of nutrients in the feed ration, and the established indicators of feed nutrient use correspond to the indicators of animal growth and feed conversion.

The leading place is occupied by nitrogen metabolism in the exchange of substances between the body and the external environment, since nitrogen is the basis of any protein structure. Nitrogen balance is the ratio of the amount of nitrogen ingested with food and excreted from it, characterizes the biological value of feed rations fed to animals and is the indicator of utilization degree for nitrogenous feed substances. Among growing animals, the nitrogen deposited in the body is used to judge the growth rate.

Based on the results of the balance experiment and the analysis of the chemical composition of feed, their residues, feces and urine, the nitrogen balance was studied, which serves as an indicator of protein use in the body of animals (table 2).

Table 2. Nitrogen balance among experimental young animals, $g$

\begin{tabular}{|l|c|c|}
\hline \multirow{2}{*}{\multicolumn{1}{|c|}{ Indicator }} & control & experimental \\
\cline { 2 - 3 } & $177,8 \pm 1,84$ & $178,1 \pm 2,37$ \\
\hline Received with feed & $68,7 \pm 4,02$ & $67,3 \pm 3,15$ \\
\hline Excreted in feces & $75,3 \pm 3,05$ & $74,2 \pm 4,11$ \\
\hline Excreted in urine & $33,8 \pm 1,59$ & $36,6 \pm 1,35$ \\
\hline Deposited in the body & $109,1 \pm 7,45$ & $110,8 \pm 8,56$ \\
\hline Digested & Feed nitrogen utilization rates, $\%:$ \\
\hline \multicolumn{2}{|c|}{} \\
\hline From taken & 19,0 & 20,5 \\
\hline From digested & 30,9 & 33,0 \\
\hline
\end{tabular}

From the results of the study concerning the exchange of nitrogenous substances in the feed ration of young fattening animals, it was found that the animals of the experimental groups consumed almost the same amount of nitrogen with the feed (Table 2). At the same time, 2.8 grams more of nitrogen was deposited in the body of the animals from the experimental group, fed with bentonite, which is $8.2 \%$ higher than among the animals of the control group. The coefficient of nitrogen utilization from that taken by the animals of the experimental group was higher by $1.5 \%$, from the digestible - by $2.1 \%$, as compared with those of the control group. The mentioned indicators of the metabolism of nitrogenous substances and their differences in the organism of the experimental groups of animals generally correspond to the compared indicators of body weight increase obtained during the scientific and economic experiment [7]. Consequently, all other conditions being equal for feeding and keeping the compared groups of experimental animals, a reliable, theoretical substantiation of feeding animals from the experimental group with bentonite 
was established, in comparison with similar indicators of young animals on fattening from the control group.

The balance of mineral substances is of great importance for the course of optimal metabolism process in the organism of animals. They are the part of enzymes, hemoglobin, phosphatides, nucleoproteins, and many other organic substances. The processes of digestion and assimilation of nutrients, metabolism and energy, regulation of osmotic pressure and maintenance of acid-base balance are directly related to the participation of minerals.

Mineral elements are considered vital for the flow of optimal processes of digestive metabolism in the body, as the catalysts for biochemical reactions: macroelements calcium and phosphorus, vital trace elements: iron, manganese, copper, zinc, cobalt, etc. Therefore, the optimal growth and development of the organism, its physiological state, the occurrence of endemic diseases and, in general, the productivity of animals depend on the content of these elements in feed rations. In connection with the above and taking into account the feeding of animals with bentonite as a partial compensator of micromineral deficiency in animal feed rations and the physicochemical properties of bentonite useful for digestion, we carried out the studies during the period of (balance) physiological experience, to study the exchange of a number of mineral elements in the body of experimental animals, the results of which are shown in table 3 .

Table 3. Average daily balance of mineral elements among experimental animals

\begin{tabular}{|c|c|c|}
\hline \multirow{2}{*}{ Indicator } & \multicolumn{2}{|c|}{ Group } \\
\hline & Control & Experimental \\
\hline \multicolumn{3}{|c|}{ Calcium, $\mathrm{g}$} \\
\hline Taken with feed & $49,35 \pm 2,22$ & $53,96 \pm 3,54$ \\
\hline Extracted: with feces & $21,63 \pm 1,33$ & $23,01 \pm 2,43$ \\
\hline with urine & $1,92 \pm 0,21$ & $2,27 \pm 0,54$ \\
\hline Total & $23,55 \pm 1,45$ & $25,28 \pm 1,77$ \\
\hline Deposited in the body & $25,8 \pm 1,67$ & $28,68 \pm 1,53$ \\
\hline$\%$ from taken & $52,28 \pm 2,54$ & $53,15 \pm 2,88$ \\
\hline \multicolumn{3}{|c|}{ Phosphorus, $\mathrm{g}$} \\
\hline Taken with feed & $28,45 \pm 2,32$ & $29,07 \pm 2.55$ \\
\hline Extracted:with feces & $11,17 \pm 1,43$ & $10,92 \pm 1,66$ \\
\hline with urine & $2,15 \pm 0,54$ & $2,43 \pm 0,53$ \\
\hline Total & $13,32 \pm 1,43$ & $13,35 \pm 1,66$ \\
\hline Deposited in the body & $15,13 \pm 1,33$ & $15,73 \pm 1,98$ \\
\hline$\%$ from taken & $53,18 \pm 3,76$ & $54,11 \pm 3,77$ \\
\hline \multicolumn{3}{|c|}{ Ferrum, mg } \\
\hline Taken with feed & $607,34 \pm 22,56$ & $632,42 \pm 26,88$ \\
\hline Extracted: with feces & $327,35 \pm 17,56$ & $326,26 \pm 23,76$ \\
\hline with urine & $19,51 \pm 3,66$ & $17,22 \pm 3,58$ \\
\hline Total & $346,86 \pm 25,66$ & $333,48 \pm 24,76$ \\
\hline Deposited in the body & $260,44 \pm 18,41$ & $288,91 \pm 21,66$ \\
\hline$\%$ from taken & $42,88 \pm 4,52$ & $45,68 \pm 4,63$ \\
\hline \multicolumn{3}{|c|}{ Manganese, $\mathrm{mg}$} \\
\hline Taken with feed & $452,31 \pm 28,41$ & $487,22 \pm 29,44$ \\
\hline Extracted: with feces & $281,32 \pm 18,52$ & $266,18 \pm 19,77$ \\
\hline with urine & $0,95 \pm 0.11$ & $0,90 \pm 0,13$ \\
\hline Total & $282,27 \pm 18,88$ & $267,08 \pm 19,43$ \\
\hline Deposited in the body & $50,5 \pm 17,76$ & $54,84 \pm 18,43$ \\
\hline$\%$ from taken & $62,45 \pm 3,49$ & $79,47 \pm 3 ., 43$ \\
\hline \multicolumn{3}{|c|}{ Copper, mg } \\
\hline Taken with feed & $84,11 \pm 3,88$ & $89,32 \pm 3,67$ \\
\hline Extracted: with feces & $34,17 \pm 1,62$ & $36,47 \pm 1,79$ \\
\hline
\end{tabular}




\begin{tabular}{|l|c|c|}
\hline with urine & $4,81 \pm 1.01$ & $3,93 \pm 1,06$ \\
\hline Total & $39,07 \pm 2,65$ & $40,02 \pm 2,76$ \\
\hline Deposited in the body & $44,93 \pm 4,89$ & $48,9 \pm 4,69$ \\
\hline \% from taken & $53,49 \pm 5,87$ & $54,73 \pm 6,00$ \\
\hline \multicolumn{2}{|c|}{ Zinc, } \\
\hline Taken with feed & $471,43 \pm 22,67$ & $490,44 \pm 23,86$ \\
\hline Extracted: with feces & $295,81 \pm 19,88$ & $299,21 \pm 21,63$ \\
\hline with urine & $12,7 \pm 2,67$ & $16,8 \pm 3,04$ \\
\hline Total & $308,5 \pm 19,87$ & $316,01 \pm 21,99$ \\
\hline Deposited in the body & $162,5 \pm 15,75$ & $174,43 \pm 21,65$ \\
\hline \% from taken & $34,5 \pm 4,75$ & $35,53 \pm 5.02$ \\
\hline \multicolumn{2}{|c|}{ Cobalt, mg } \\
\hline Taken with feed & $6,85 \pm 1,76$ & $7,39 \pm 2,08$ \\
\hline Extracted: with feces & $3,17 \pm 1,65$ & $3,28 \pm 2,60$ \\
\hline with urine & $0,41 \pm 0,02$ & $0,59 \pm 0,07$ \\
\hline Total & $3,58 \pm 1.11$ & $3,87 \pm 1,68$ \\
\hline Deposited in the body & $3,27 \pm 1,63$ & $3,52 \pm 1,52$ \\
\hline \% from taken & $47,74 \pm 11,65$ & $47,70 \pm 12,66$ \\
\hline
\end{tabular}

The inclusion of bentonite clay from the Zamankul deposit in the diets of young cattle for fattening contributed to the increase of mineral element content in the feed and their use in the body of animals from the experimental group, in relation to the control one.

From the results given in Table 3 it follows that the amount of calcium taken with feed by animals of the experimental group increased by $9.3 \%(\mathrm{P} \leq 0.001)$, phosphorus - by $1.0 \%$ $(\mathrm{P} \geq 0.01)$, iron - by $4.1 \%(\mathrm{P} \geq 0.01)$, manganese - by $7.7 \%(\mathrm{P} \leq 0.01)$, copper - by $6.1 \%(\mathrm{P} \leq$ $0.01)$, zinc - by $4.0 \%(\mathrm{P} \geq 0.01)$ and cobalt - by $7.9 \%(\mathrm{P} \leq 0.001)$ as compared to the control group.

At the same time, they noted a significantly large retention of mineral elements in the body of the animals from the experimental group, with the exception of the macronutrient phosphorus: $\mathrm{Ca}-11.1 \%(\mathrm{P} \leq 0.001) ; \mathrm{P}-3.9 \%(\mathrm{P} \geq 0.01) ; \mathrm{Fe}-10.9 \%(\mathrm{P} \leq 0.001) ; \mathrm{Mn}-8.5 \%$ $(\mathrm{P} \leq 0.01) ; \mathrm{Cu}-8.8 \%(\mathrm{P} \leq 0.01) ; \mathrm{Zn}-7.3 \%(\mathrm{P} \leq 0.01)$ and $\mathrm{Co}-7.6 \%(\mathrm{P} \leq 0.01)$. Accordingly, the studied mineral elements were better used from those taken with food in the body of the animals from the experimental group, with the exception of phosphorus in relation to the animals of the control group.

Analyzing the results shown in Table 3, obtained during the study of mineral element exchange in the body of animals fed with bentonite, it follows that the inclusion of bentonite clay from the Zamankul deposit in the composition of the feed ration of young cattle for fattening contributed to a better assimilation and use of mineral elements, as compared with the animals of the control group.

\section{Conclusions}

1. The coefficients of nutrient digestibility among young fattening cattle fed with bentonite clay along with the ration is slightly higher than that of their counterparts in the control group: dry matter - by $2.2 \%$; organic matter - by $3.5 \%$; protein - by $2.4 \%$; fat - by $2.8 \%$; fiber - by $1.8 \%$ and NFES - by $2.7 \%$.

2. The addition of bentonite feeding to the diet of young cattle contributed to the better use of nitrogen by the experimental group, as compared with the control one: nitrogen retention in the body of animals increased by $2.8 \mathrm{~g}(8.2 \%)$, nitrogen from the accepted one by $1.5 \%$, from digested - by $2.1 \%$.

3. The feeding of young cattle with bentonite clay from the Zamankul deposit provided a significantly greater deposition in the body of the animals from the experimental group: 
calcium increased by $11.1 \%$, phosphorus - by $1.9 \%$, iron - by $10.9 \%$, manganese - by $8.5 \%$, copper $-8.8 \%$, zinc $-7.3 \%$, and cobalt $-7.6 \%$.

\section{References}

1. V.A. Alikaev, E.A. Petukhova, L.D. Khaleneva, et al, Handbook on the control of feeding and keeping animals, 320 (1982)

2. B.A. Dzagurov, A.G. Karlov, B.A. Dzagurov, Bulletin of the Gorsk State Agrarian University, 57(2), 97 (2020)

3. V. F. Vasiliev, V. N. Struganov, Yu. P. Kozlov, In Sb.: Natural zeolites in the national economy. Proc. All-Union. the meeting, 18 (1990)

4. V. K. Gorokhov, Far East, 104 (1982)

5. B.A. Dzagurov, R.Kh. Gadzaonov, A.G. Karlov, Bulletin of the Mountain State Agrarian University, 57(1), 54 (2020)

6. S.A. Lapshin, Chemicalization of agriculture, 8, 62 (1988)

7. B.A. Dzagurov, A.G. Karlov, News of the Gorsky State Agrarian University, 57(2), 50 (2020)

8. B.A. Dzagurov, Z.A. Ktsoeva, Bentonite feeding of pigs, 185 (2018)

9. V. V. Kalashnikov, Dairy and meat cattle breeding, 1, 2 (2010) 